\title{
COVID-19 in pregnancy, management and outcomes among pregnant women and neonates - results from tertiary care center in Wroclaw
}

\author{
Paulina Szczygiol ${ }^{1}$, Karolina Baranska ${ }^{1}$, Ilona Korczak ${ }^{1}$, Aleksandra Zimmer-Stelmach ${ }^{2} \mathbb{D}$,

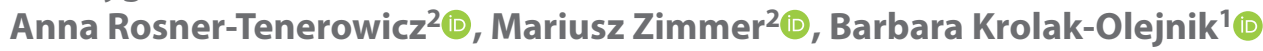 \\ ${ }^{1}$ Department and Clinic of Neonatology Wroclaw Medical University \\ ${ }^{2} 2^{\text {nd }}$ Department and Clinic of Gynecology and Obstetrics Wroclaw Medical University
}

\begin{abstract}
Objectives: A novel coronavirus - SARS-CoV-2 - outbreak has, for sure, been the greatest medical challenge in recent years. The maternal and neonatal consequences of the infection are still largely unknown.

Material and methods: This prospective study aims to describe the perinatal care and outcomes of SARS-CoV-2 positive pregnant women and their newborn infants during the third wave of the pandemic, in a large tertiary university center in Wroclaw/Poland from 15 February to 1 May 2021.

Results: The paper describes a group of 83 women with confirmed SARS-CoV-2 infection during delivery, as well as their newborn infants $(n=84)$. The course of COVID-19 disease in pregnant patients was mostly asymptomatic $(54.2 \%)$ but $31 \%$ women manifested mild to moderate symptoms and $14 \%$ had severe infection. The median gestational age at the delivery was 39 weeks. On average, $16.7 \%$ of mothers were separated from their newborns at birth, $83.3 \%$ practiced skin-to-skin, and roomed in with their babies, and $84.5 \%$ of the infants received any mother's milk. Preterm infants were more often born by mothers with symptomatic course of COVID-19 infection. Need for neonatal treatment was only due to prematurity. Neonates with acquired infection (after $14^{\text {th }}$ day of life) had to be treated symptomatically with fever and loose stools, only $28.5 \%$ had symptoms of respiratory failure.

Conclusions: Despite the confirmed SARS-CoV-2 infection, the majority of mother- infant dyads were in a good health condition. The data on perinatal care reported in the paper could be helpful contribution supporting childbirth physiology protection during the COVID-19 pandemic.
\end{abstract}

Key words: COVID-19; perinatal care; SARS-CoV-2; neonate; pregnancy outcomes

Ginekologia Polska 2022; 93, 1: 47-53

\section{INTRODUCTION}

Identification of the novel coronavirus known as severe acute respiratory syndrome coronavirus 2 [SARS-CoV-2] has led to concerns about obstetrical patients and neonates as the data regarding COVID-19 infection in these populations were limited. Both groups represent a unique at-risk population, where pregnant women could be at increased risk for severe illness from COVID-19 compared to non-pregnant women, and newborns are potentially exposed to infection in utero, intrapartum, and postpartum [1]. Leading international health agencies and professional societies recommendations concerning the management of suspected or confirmed SARS-CoV-2 pregnant women and their infants were changing over time. Firstly, strict infection control measures were taken to reduce the perinatal transmission [2]. Clinical practices included elective cesarean delivery, separation of newborn and temporary suspension of breastfeeding [3]. Subsequent recommendations have appeared in April 2020 pointing the mode of delivery should be individualized due to obstetric and fetal indications and must not be impacted by COVID-19 infection unless worsening COVID-19 symptoms require urgent delivery. Neither Caesarean nor vaginal birth should be favored as there is no evidence of superiority of one mode of

\section{Corresponding author:}

Paulina Szczygiol

Department of Neonatology Wroclaw Medical University, University Hospital, 213 Borowska St, 50-556 Wrocław, Poland

e-mail: pszczygiol@usk.wroc.pl 
delivery over another [4]. The presence of a support person during active labor should not be contraindicated as it could improve birth outcomes for both mothers and infants. Hospitals should ensure universal testing as much as possible, not only for the woman but also for her birth partner [5]. The usage of personal protective equipment by patients and health workers during all procedure is obligatory. In the postpartum period, practices like skin-to-skin contact, rooming-in, and breastfeeding are all recommended unless the mother or neonate require additional medical care. These practices also do not increase the risk of neonatal infection with SARS-CoV-2. Mothers with COVID-19 should follow hand hygiene rules and wear a surgical mask to minimize any risk of virus transmission, especially while breastfeeding when close contact is maintained [4, 6]. Long term benefits of breastfeeding outweigh any potential risks of transmission of the virus through breast milk. Therefore, women should be encouraged to breastfeed or in cases when direct breastfeeding is impossible, the collection of the milk by using breast pumps should be suggested [7].

Our hospital followed the statements of National Consultants in the field of Obstetrics and Gynecology, Neonatology, as well as President of the Polish Society of Obstetricians and Gynecologists and President of the Polish Neonatology Society. Subsequently pregnancies with confirmed SARS-CoV-2 infection for epidemiological indications were mostly managed by performing a caesarean section, with exception for situations of advanced, dynamic deliveries [8]. In Poland, the presence of a birth support person depends on the decision made by the head of hospital in consultation with the head of Obstetrics and Gynecology Ward and in our hospital was not permitted.

According to the recommendations of the Polish Neonatal Society, the procedures after birth in a mother diagnosed with COVID-19 depends on factors such as the mother's health, the health of the newborn, the mother's decision, as well as the type of departments and the resulting human resources and the availability of protective measures. Following the recommendations newborns of SARS-CoV-2 positive mothers were bathed immediately after delivery to reduce the risk of virus transmission. If the child was clinically in good condition, a decision was made to delay cord severance, irrespective of the result of the mother's SARS-CoV-2 test. Skin-to-skin contact lasting two hours, or more was practiced unless the health of the mother and child required immediate intervention. Depending on the clinical condition of the mother and baby, newborn infants, stayed with their mothers in rooming-in system and were fed naturally [9].

\section{Objectives}

Despite publication of a consistent international recommendations which significantly helped making medical decisions, management of COVID-19 in pregnant patients and their newborns differ among hospitals. Also, the data regarding perinatal consequences and infection's impact on pregnant women and neonates born to SARS-CoV-2 positive mothers are limited. The study aims to describe how the $2^{\text {nd }}$ Department of Gynecology and Obstetrics and Department of Neonatology in Wroclaw Medical University Teaching Hospital were providing perinatal care to pregnant women with COVID-19 and their neonates and present the mothers' and newborns' health evaluation and related outcomes.

\section{MATERIAL AND METHODS}

Between 15 February and 01 May 2021 Wroclaw Medical University Teaching Hospital was classified as a hybrid hospital for all Lower Silesia region for both COVID-19 and non-COVID-19 patients. Data regarding all pregnant women and their newborns analyzed in this study came from that time frame. In this study only pregnant women with confirmed SARS-CoV-2 infection were included. Based on regulations given by Polish Ministry of Health universal testing of pregnant women for SARS-CoV-2 was performed at hospital admission office using RT-qPCR test. Infants born to SARS-CoV-2 positive mothers were universally screened within 24 hours at birth. If the test results were inconclusive the next nasopharyngeal swab was taken at least 24 hours after the first test. Electronic hospital records were used to collect the data on maternal characteristics, maternal and perinatal outcomes, and information about procedures after birth e.g., mother-newborn separation, skin-to-skin contact, breastfeeding, and rooming-in and the need for exacerbating treatment in the Intensive Care Unit. All patient's data were analyzed anonymously. Approval was obtained from the Bioethics Committee of the Wrocław Medical University (KB-338/2021) for the retrospective analysis of all data concerning patients with COVID-19. The collected data was processed using the STATISTICA 13 package (license number JPZ903B482814ARACD-5).

\section{RESULTS}

\section{Maternal characteristics}

The data analysis included 83 women who gave birth with confirmed SARS-CoV-2 infection, of which $54.2 \%$ were asymptomatic. Thirty-eight women (45.8\%) had symptomatic COVID-19 infection; 26 of women manifested mild to moderate symptoms and 12 had severe infection symptoms. The most commonly reported symptoms were cough- $63.2 \%$, fever - 50\%, dyspnea - 39.5\%, weakness - $21.1 \%$, rhinitis $-13.2 \%$, headache, loss of taste and smell $-10.5 \%$, muscle aches $-7.9 \%$, sore throat, shivers, tightness of the chest, vomiting, diarrhea, nausea, thrombocytopenia - 2.6\% (Fig. 1).

Data regarding obstetric patients are presented in Table 1. The median age for all women analyzed in the study was 


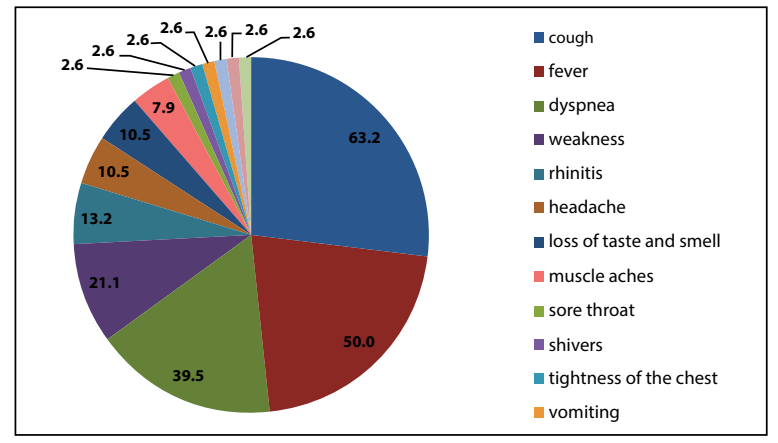

Figure 1. The most reported symptoms of COVID-19 among infected women

\begin{tabular}{|c|c|}
\hline Feature & $\begin{array}{l}\mathrm{n}=83 \\
\text { no. [\%] }\end{array}$ \\
\hline \multicolumn{2}{|l|}{ Age (y) } \\
\hline$\leq 29$ & $31(37.3)$ \\
\hline $30-34$ & $36(43.4)$ \\
\hline$\geq 35$ & $16(19.3)$ \\
\hline Median, range & $31,23-44$ \\
\hline \multicolumn{2}{|c|}{ Pre-existing comorbidities } \\
\hline Yes & $21(25.3)$ \\
\hline No & $62(74.7)$ \\
\hline \multicolumn{2}{|c|}{ Pregnancy morbidities } \\
\hline Yes & $25(30.1)$ \\
\hline No & $58(69.9)$ \\
\hline \multicolumn{2}{|c|}{ Symptoms of COVID } \\
\hline Yes & $38(45.8)$ \\
\hline Mild/moderate & $26(68,4)$ \\
\hline Severe & $12(31.6)$ \\
\hline No & $45(54.2)$ \\
\hline \multicolumn{2}{|l|}{ Gravida } \\
\hline 1 & $29(34.9)$ \\
\hline 2 & $39(47.0)$ \\
\hline$>3$ & $15(18.1)$ \\
\hline Median, range & $2,1-5$ \\
\hline \multicolumn{2}{|c|}{ Multiple pregnancies } \\
\hline Yes & $1(1.2)$ \\
\hline No & $82(98.8)$ \\
\hline
\end{tabular}

31 years (23-44). Sixteen pregnant patients admitted to the department due to COVID-19 infection were over 35 years of age, which constituted $19.3 \%$ of the women participating in the study. Pre-existing disease was found in 21 (25.3\%) patients positive to COVID-19. The most reported chronic disorders were hypothyroidism, hypertension, cardiac diseases, diabetes mellitus, insulin resistance, thrombophilia,
Hashimoto, Graves-Basedow disorder. Pregnancy related pathologies were marked in $30.1 \%$ of the patients, out of which gestational diabetes - 24\%, pregnancy induced hypertension - 20\%, hypothyroidism - 28\%, anaemia - $20 \%$, insulin resistance and pregnancy cholestasis - $2 \%$. One woman was suspected of a preeclampsia, but eventually no pharmacotherapy was needed and implemented. Women participating in the study were mainly in their second pregnancy (47.0\%).

\section{Maternal and perinatal outcomes}

During labor women wore surgical masks and health workers used personal protective equipment. Considering the pandemic situation and decision made by the head of the hospital and principal epidemiologist of hospital the presence of a birth support partner was not permitted. The mode of delivery was mostly caesarean section. The average caesarean section (CS) rate was $68.7 \%$, of which elective CS was $10.5 \%$; urgent/emergency CS due to maternal and fetal indications was performed in $89.5 \%$; CS solely due to COVID-19 was performed in $19.3 \%$.

Median gestational age at the delivery was 39 weeks. $81.9 \%$ deliveries occurred at term and $18.1 \%$ were preterm births. Among 15 preterm births, 9 (60\%) came from symptomatic COVID-19 mothers - six premature babies were born to mothers with severe COVID-19 symptoms and three were born to mothers with mild/moderate symptoms of infection. 11 pregnancies were delivered due to an exacerbation of COVID-19 infection.

Six mothers (7.2\%) were admitted to the Intensive Care Unit. Four mothers required mechanical ventilation and two were qualified to Extra Corporeal Membrane Oxygenation (ECMO). Among adverse maternal outcomes premature rupture of membrane was reported in 11 cases (13.1\%), three cases occurred among symptomatic and eight cases among asymptomatic pregnant women. Most women were discharged home without complications. Two maternal deaths due to COVID-19 infection were reported (2.4\%). The data analysis is presented in Table 2.

\section{Neonatal characteristics}

The study describes outcomes of 84 neonates born to SARS-CoV-2 positive mothers and 7 newborns with confirmed SARS-CoV-2 COVID-19 infection admitted to Department and Clinic of Neonatology. Sixty-eight infants were born at term and 15 were preterm. Two newborns come from twin pregnancy. All the positive mother's neonates were born alive. Infants born to SARS-CoV-2 positive mothers were universally screened within 24 hours at birth. If the RT-qPCR test result were inconclusive the next nasopharyngeal swab was taken at least 24 hours after the first test. No positive SARS-CoV-2 test results were reported among infants born in our hospital. Initially, seven neonates tested positive after 


\begin{tabular}{|c|c|}
\hline Feature & $\begin{array}{l}n=83 \\
\text { no. [\%] }\end{array}$ \\
\hline \multicolumn{2}{|l|}{ Deliveries } \\
\hline Total term birth & $68(81.9)$ \\
\hline Total preterm birth & $15(18.1)$ \\
\hline \multicolumn{2}{|c|}{ Asymptomatic women: } \\
\hline Term birth & 39 (86.7) \\
\hline Preterm birth & $6(13.3)$ \\
\hline \multicolumn{2}{|c|}{ Symptomatic women: } \\
\hline \multicolumn{2}{|l|}{ Mild/moderate } \\
\hline Term birth & $24(63.1)$ \\
\hline Preterm birth & $3(7.9)$ \\
\hline \multicolumn{2}{|l|}{ Severe } \\
\hline Term birth & $5(13.2)$ \\
\hline Preterm birth & $6(15.8)$ \\
\hline \multicolumn{2}{|l|}{ Mode of Delivery } \\
\hline Cesarean section & $57(68.7)$ \\
\hline Vaginal & $26(31.3)$ \\
\hline \multicolumn{2}{|c|}{ Indications for caesarean section } \\
\hline Elective & $6(10.5)$ \\
\hline Urgent/emergency: & $51(89.5)$ \\
\hline Maternal $^{1}$ & $10(17.5)$ \\
\hline Obstetric $^{2}$ & 27 (47.4) \\
\hline Fetal $^{3}$ & $9(15.8)$ \\
\hline $\operatorname{COVID}^{4}$ & $11(24.1)$ \\
\hline ICU admission & $6(7.2)$ \\
\hline \multicolumn{2}{|l|}{ Mother's death } \\
\hline Yes & $2(2.4)$ \\
\hline No & $81(97.6)$ \\
\hline \multicolumn{2}{|c|}{$\begin{array}{l}{ }^{1} \text { cholestasis gravidarum, hypertension, } \mathrm{PIH} \text {, vaginal septum, cardiological } \\
\text { indication; }{ }^{2} \text { labor dystocia, the risk of scar dehiscence after previous } \\
\text { cesarean section, intrauterine infection, bleeding; }{ }^{3} \text { abnormal fetal heart rate } \\
\text { tracing, the risk of intrauterine fetal asphyxia, fetal malpresentation, multiple } \\
\text { gestation; }{ }^{4} \text { severe course of COVID infections }\end{array}$} \\
\hline
\end{tabular}

birth, but second tests repeated after $24 \mathrm{~h}$ were all negative. One of the infants was re-hospitalized on the $15^{\text {th }}$ day of life due to COVID-19 infection and it is likely the infection was acquired postpartum from mother. NICU admission was necessary in 18 cases (21.4\%). In all newborn infants, respiratory support was required. In order to enable efficient breathing of (16.7\%) newborns, non-invasive ventilation (nCPAP) was used. $9.5 \%$ of newborns required support for the adaptation period through lung inflation. For $10.7 \%$ newborns, oxygen therapy was needed. One neonate required resuscitation. Due to clinical state and respiratory failure, $4.8 \%$ of neonates required intubation and invasive mechanical ventilation. During hospitalization, 13 (15.5\%) neonates were observed and monitored for vital functions in incubators. (Tab. 3).

\begin{tabular}{|c|c|}
\hline Feature & $\begin{array}{l}n=84 \\
\text { no. [\%] }\end{array}$ \\
\hline \multicolumn{2}{|l|}{ Gestational age at birth [w] } \\
\hline$<28$ & $1(1.2)$ \\
\hline $28-32$ & $5(6.0)$ \\
\hline $33-36$ & $9(10.7)$ \\
\hline$\geq 37$ & $69(82.1)$ \\
\hline Median, range & $39,26-41$ \\
\hline \multicolumn{2}{|l|}{ Birth weight [g] } \\
\hline$<1500$ & $4(4.8)$ \\
\hline $1500-2499$ & $8(9.5)$ \\
\hline$\geq 2500$ & $72(85.7)$ \\
\hline Median, range & $3360,850-4460$ \\
\hline \multicolumn{2}{|l|}{ Birth weight for gestational age } \\
\hline LGA & $9(10.7)$ \\
\hline AGA & $64(76.2)$ \\
\hline $\begin{array}{l}\text { SGA: } \\
\text { LBW } \\
\text { VLBW } \\
\text { ELBW }\end{array}$ & $\begin{array}{l}11(13.1) \\
7(63.6) \\
3(27.2) \\
1(9.1)\end{array}$ \\
\hline \multicolumn{2}{|l|}{ Sex } \\
\hline Male & $47(56.0)$ \\
\hline Female & $37(44.0)$ \\
\hline \multicolumn{2}{|l|}{ Apgar at minute 1} \\
\hline $1-3$ & $1(1.2)$ \\
\hline $4-6$ & $6(7.1)$ \\
\hline $7-10$ & 77 (91.7) \\
\hline Median & 10 \\
\hline \multicolumn{2}{|l|}{ Apgar at minute 5} \\
\hline $1-3$ & $1(1.2)$ \\
\hline $4-6$ & $2(2.4)$ \\
\hline $7-10$ & $81(96.4)$ \\
\hline Median & 10 \\
\hline \multicolumn{2}{|l|}{ NICU admission } \\
\hline Yes & $18(21.4)$ \\
\hline No & $66(78.6)$ \\
\hline \multicolumn{2}{|l|}{ Ventilation } \\
\hline Yes & $18(20.2)$ \\
\hline No & $66(79.8)$ \\
\hline Non-invasive ventilation & $14(77.8)$ \\
\hline Invasive ventilation & $4(22.2)$ \\
\hline Oxygen & $9(50.0)$ \\
\hline \multicolumn{2}{|l|}{ Respiratory morbidities } \\
\hline None & 75 (89.3) \\
\hline Tachypnea & $2(2.4)$ \\
\hline Virus RSV & $1(1.2)$ \\
\hline Respiratory distress syndrome & $5(6.0)$ \\
\hline Pneumothorax & $1(1.2)$ \\
\hline \multicolumn{2}{|l|}{ Separated from the mother } \\
\hline Yes & $14(16.7)$ \\
\hline No & $70(8.3)$ \\
\hline \multicolumn{2}{|l|}{ Any Breast-feeding } \\
\hline Yes & $71(84.5)$ \\
\hline No & $12(14.3)$ \\
\hline Missing data & $1(1.2)$ \\
\hline Donor Milk (Human Milk Bank) & $6(7.1)$ \\
\hline
\end{tabular}


Average length of infant's hospitalization reached 7.4 days (medium 4) and included preterm as well. Majority of neonates were discharged home without any complications, one negative neonate from a positive mother, was still admitted at the time of this analysis (born April 04, 2021). During the hospital stay, $14 / 84$ of newborns (16.7\%) were separated from their mothers as the infants or mothers required additional medical care. The rest of infants practiced skin-to-skin contact and stayed with their mother in the rooming-in system (Tab. 3).

Out of 84 newborns, 71 were breastfed and 61 of neonates were additionally fed with milk formula or milk from Human Milk Bank were used ( 6 premature). The median age of pregnancy was 39 (26-41) weeks. The median birth weight of newborns was $3360 \mathrm{~g}$ (850-4460 g). In the case of mothers with COVID-19, most newborns were born appropriate for gestational age (75.0\%). Eleven newborns were born too small and nine too big for gestational age. Most newborns scored 7-10 on the Apgar scale at 1 and 5 minutes after delivery (Tab. 3).

\section{Neonates with acquired COVID-19 infection}

Eight infants were admitted to the Department and Clinic of Neonatology due to COVID-19 symptoms or positive rapid antigen test results. RT-qPCR made after hospital admission tested positive in seven cases. One of the neonates was born in our hospital and re-hospitalized on the 15th day of life due to COVID-19 infection. Two infants came from COVID-19 positive mothers, two with COVID-19 symptoms but without test, two from quarantine parents and one infant with hospital acquired infection. Five infants were admitted to NICU, and two infants were asymptomatic SARS-CoV-2 infection roomed-in with their infected mother. Symptoms and treatment of infected infants are shown in Table 4.

\section{DISCUSSION}

This paper describes the management of mothers and newborns during the COVID-19 pandemic at the Second Department of Gynecology and Obstetrics and Department of Neonatology at Wroclaw Medical University Hospital.

The majority of reported worldwide pregnant SARS-CoV-2 positive women have asymptomatic course of infection. Study from the USA estimated that over $86 \%$ of pregnant women who tested positive for SARS-CoV-2 during labour were asymptomatic [10]. Another study, Preg-CoV-19 Living Systematic Review that include almost 65,000 pregnant women reported $74 \%$ of asymptomatic infection among this group of patients basing on universal screening and testing [11]. In our study $54.2 \%$ pregnant women were asymptomatic. Among symptomatic women $31.6 \%$ manifested severe symptoms- the cases
Table 4. Data of newborns with confirmed SARS-CoV-2 infection

\begin{tabular}{|l|l|}
\hline Features & $\begin{array}{l}\text { Infected newborns } \mathbf{n = 7} \\
\text { no. [\%] }\end{array}$ \\
\hline $\begin{array}{l}\text { Gestational age (weeks) } \\
\text { Median, range }\end{array}$ & $37,27-39$ \\
\hline $\begin{array}{l}\text { Preterm birth } \\
\text { Caesarean section }\end{array}$ & $2(28.6)$ \\
\hline $\begin{array}{l}\text { Birth weight [grams] } \\
\text { Median, range }\end{array}$ & $3(42.8)$ \\
\hline $\begin{array}{l}\text { Apgar score, median } \\
1^{\prime}\end{array}$ & $2872.5 ; 750-3800$ \\
\hline $5^{\prime}$ & 10 \\
\hline Symptoms & 10 \\
\hline $\begin{array}{l}\text { Fever } \\
\text { Respiratory failure }\end{array}$ & \\
\hline $\begin{array}{l}\text { Apathy } \\
\text { Rhinitis } \\
\text { Inflammatory changes in chest X-ray } \\
\text { Loose stools }\end{array}$ & $1(14.3)$ \\
\hline $\begin{array}{l}\text { Treatment } \\
\text { Oxygen }\end{array}$ & $2(100)$ \\
\hline $\begin{array}{l}\text { Non-invasive ventilation } \\
\text { Antibiotics } \\
\text { Paracetamol }\end{array}$ & $2(28.6)$ \\
\hline & $3(42.9)$ \\
\hline & $1(14.3)$ \\
\hline & $2(28.6)$ \\
\hline & $4(57.1)$ \\
\hline
\end{tabular}

we present confirm that most of the symptomatic women manifest only mild to moderate symptoms of infection [12]. The Allotey review reported that fever (40\%), cough (39\%) and dyspnea (19\%) were the most common symptoms [11]. Similar results were observed in our hospital: cough (63.2\%), fever (50\%) and dyspnea (39.5\%).

Women with symptomatic COVID-19 infection are at increased risk of caesarean birth and fetal distress during active labour $[13,14]$. The average caesarean section rate in Italian study (Donati et al. [15]) was 33.7\%; elective CS was performed in $15.4 \%$ of the cases; urgent/emergency CS due to maternal or fetal indications was performed in 15\% and due to COVID-19 was performed in $3.3 \%$ of the cases. In another study conducted in Mexico City (Cardona- Perez et al. [16]) CS rate reached $81 \%$ among SARS-CoV-2 positive women comparing to non-infected pregnant women (73\%). Indications for CS among COVID-19 positive women were firstly, solely maternal (40\%) then fetal (31\%) and lastly obstetrical (18\%). CS rate in our hospital reached $68.7 \%$, among which elective CS was performed in 10,5\%, urgent/emergency due to maternal or fetal indications $89,5 \%$; due to worsening COVID-19 disease 19.3\% [16].

Pregnant women (especially in the third semester) may be at increased risk of more severe course of the COVID-19 disease compared with non-pregnant women. An increase in ICU admission and mechanical ventilation among pregnant woman with COVID-19 comparing to non-pregnant women is notable (respectively OR 1.62, 95\% 
Cl 1.33-1.96 OR 1.88, 95\% Cl 1.36-2.60) [17]. The Allotey review reported that admission to an intensive care unit was $4 \%$ and $3 \%$ required invasive ventilation. ICU admission in our hospital was necessary in $7,2 \%$ and invasive ventilation was required in $4.8 \%$ cases [11].

In a large retrospective US study comparing the outcomes for pregnant women with and without COVID-19 maternal death was rare, but rates were significantly higher for women with COVID-19 (141 deaths per 100000 women) than for women without COVID-19 (5 deaths per 100000 women) [18]. Another study from the Washington State reported 13.6 fold higher SARS-CoV-2 case-fatality rate for pregnant women with COVID-19 (maternal mortality rate of 1250 of 100,000 pregnancies) than for non-pregnant controls (91.7 of 100,000 rate) [19]. In our hospital we reported 2 maternal deaths (2.4\%) due to COVID-19.

There are several studies that look for the relationship between COVID-19 disease and pregnancy or neonatal outcomes. SARS-CoV-2 infection in pregnancy seems to be associated with increased risks of preeclampsia, stillbirth, preterm birth, premature rupture of membrane and NICU admission. In the Cardona-Pérez et al. study, an increased risk of preeclampsia in women with SARS-CoV-2 infection was found [16]. In our study group, only one woman $(0.01 \%$ of respondents) was suspected of having pre-eclampsia, which does not allow us to confirm the conclusion of quoted Cardona-Pérez et al. [16] the thesis that SARS-CoV-2 infection increases the risk of pre-eclampsia. In this study, also increased risk of premature rupture of membrane (PROM) was reported. The prevalence of those adverse outcomes among positive pregnant women was $12 \%$. Another study reported the prevalence of PROM the level of $15.4 \%$ [20]. In our study PROM was observed in $13.1 \%$ cases.

Chen et al. [21] reported a $20 \%$ preterm birth incidence (out of 118 pregnancies) in SARS-CoV-2 positive patients, but no vertical transmission. Another study by Allotey et al. showed that the rate of preterm birth reported among pregnant women diagnosed with COVID-19 was 17\% [11]. The frequency of preterm birth in our hospital was $18,1 \%$. Six newborns were born by mothers with severe symptoms of infections and three from mothers with mild/moderate symptoms.

In Italy, it was found that appropriate, physiologically compatible treatment of a pregnant woman infected with SARS-CoV-2 may lead to reducing the rate of unnecessary Caesarean sections, separation of mothers from newborns and delayed breastfeeding. For this reason, the authors encourage that both during the current pandemic and similar situations in the future, emphasis should be placed on creating a protective mother-newborn relationship [15].
Potential routes of perinatal SARS-CoV-2 infection include infection through placenta, contact with maternal secretions during delivery, through droplets after delivery, and during breastfeeding. However, perinatal infections are rare. According to current research, the percentage of infected newborns ranges from $2.2 \%$ to $9.1 \%$ [1, 15, 23]. In our hospital no positive SARS-CoV-2 test result among infants just after delivery was reported.

Researchers found a statistical correlation between a positive COVID-19 test in the mother and/or newborn and the birth weight to gestational age ratio, the need to stay in the neonatal intensive care unit, the occurrence of respiratory diseases and the length of hospitalization [16]. In our hospital $85.7 \%$ of newborns weighed $\geq 2500$ and median Apgar score at 1. and 5. minutes was 10 . Similarly in another study $86 \%$ newborns weighed $\geq 2500$ and the medium Apgar index was 9 at 1 minute and 10 at minute 5 (15). Also, in a study conducted in Mexico City $81 \%$ newborns weighed $\geq 2500$ [16].

One of the adverse neonatal outcomes observed among neonates born to SARS-CoV-2 positive mother is a necessity of NICU admission. Such a necessity in our hospital occurred in 18 cases (21.4\%), which is comparable to another studies e.g., Nayak et al. [11] - 23\%, Allotey et al. [20] $-25 \%$.

Donati et al. [15] reported that among neonates born to SARS-CoV-2 positive mothers $2.2 \%$ developed severe morbidity, acute respiratory distress syndrome and interstitial pneumonia. Zhu et al. [23] reported that newborns ( $n=10)$ born to mothers with confirmed COVID-19 infection developed shortness of breath $(n=6)$, fever $(n=2)$, thrombocytopenia accompanied by disrupted liver function $(n=2)$, rapid heart rate $(n=1)$, vomiting $(n=1)$, and pneumothorax $(n=1)$. In our hospital in all newborns admitted to NICU, respiratory support was required. Among adverse outcomes respiratory distress syndrome $-6 \%$, pneumothorax $-1.2 \%$ and one neonate required resuscitation. Current evidence suggest that development of severe COVID-19 in neonates and children is rare, and to date there is no evidence for congenital abnormalities associated with maternal infection.

In Nayak et al. [20] study, out of 165 neonates $138(83.6 \%)$ roomed-in with mother and initiated breast feeding. Next study describing 525 SARS-CoV-2 positive women, reported that $39 \%$ of them were separated from their newborns at birth; $26.6 \%$ practiced skin-to-skin contact; $72.1 \%$ were able to room in with their babies; and $79.6 \%$ of the infants received their mother's milk, $69 \%$ by direct breast-feeding and $10.6 \%$ by pumping or expressing breastmilk [15]. Results from our hospital were as follows: $14 / 84$ of newborns (16.7\%) were separated from their mothers as the infants or mothers required additional 
medical care. The rest of the infants practiced skin-to-skin contact and stayed with their mother in the rooming-in system. 71 (84.5\%) neonates were any breastfed, 6 preterm neonates received donor milk from Human Milk Bank (2 of them over 2 months).

\section{CONCLUSIONS}

At the beginning of the pandemic, the limited evidence regarding treatment of pregnant women and newborns with a confirmed or even suspected COVID-19 led to a "better safe than sorry" care choices. Today, however, the evidence shows that respecting physiology in women with confirmed or suspected SARS-CoV-2 infection during labour and delivery avoids unnecessary cesarean section, early mother-infant separation, and formula feeding unless the severity of the women's clinical conditions requires such decisions. The data on management of pregnant woman and early newborn care reported in the paper could be helpful contribution supporting childbirth physiology protection during the COVID-19 pandemic. These data, together with the available evidence on COVID-19, will support health professionals in their daily work and provide an opportunity for decision makers to properly manage the next waves of the COVID-19 pandemic.

\section{Acknowledgments \\ Not applicable.}

\section{Conflict of interest}

The authors declare no conflict of interest.

\section{Financial disclosure}

The authors receive no financial support for the study conduct.

\section{REFERENCES}

1. Mark EG, McAleese S, Golden WC, et al. Coronavirus Disease 2019 in Pregnancy and Outcomes Among Pregnant Women and Neonates: A Literature Review. Pediatr Infect Dis J. 2021; 40(5): 473-478, doi: 10.1097/INF.0000000000003102, indexed in Pubmed: 33847297

2. Wang S, Guo L, Chen L, et al. A Case Report of Neonatal 2019 Coronavirus Disease in China. Clin Infect Dis. 2020; 71(15): 853-857, doi: 10.1093/cid/ciaa225, indexed in Pubmed: 32161941.

3. Chen D, Yang $\mathrm{H}, \mathrm{Cao} \mathrm{Y}$, et al. Expert consensus for managing pregnant women and neonates born to mothers with suspected or confirmed novel coronavirus (COVID-19) infection. Int J Gynaecol Obstet. 2020; 149(2): 130-136, doi: 10.1002/ijgo.13146, indexed in Pubmed: 32196655.

4. Royal College of Obstetricians and Gynaecologists (RCOG). The Grants Register 2021. 2020: 713-721, doi: 10.1057/978-1-349-95988-4_760.

5. Bohren $\mathrm{MA}$, Berger $\mathrm{BO}$, Munthe-Kaas $\mathrm{H}$, et al. Perceptions and experiences of labour companionship: a qualitative evidence synthesis. Cochrane Database Syst Rev. 2019; 3: CD012449, doi: 10.1002/14651858. CD012449.pub2, indexed in Pubmed: 30883666.

6. Williams J, Namazova-Baranova L, Weber M, et al. The Importance of Continuing Breastfeeding during Coronavirus Disease-2019: In Support of the World Health Organization Statement on Breastfeeding during the Pandemic. The Journal of Pediatrics. 2020; 223: 234-236, doi: 10.1016/j. jpeds.2020.05.009.
7. Vassilopoulou E, Feketea G, Koumbi L, et al. Breastfeeding and COVID-19: From Nutrition to Immunity. Frontiers in Immunology. 2021; 12, doi: 10.3389/fimmu.2021.661806.

8. Rekomendowana ścieżka postępowania dla kobiet w ciąży COVID-19. https://www.ptgin.pl/rekomendowana-sciezka-postepowania-dla-kobiet-w-ciazy-covid-19.

9. Zalecenia Polskiego Towarzystwa Neonatologicznego Krajowego Nadzoru w dziedzinie neonatologii. (2020) Postępowanie z noworodkiem przy podejrzeniu/potwierdzeniu zakażenia SARS-CoV-2 u matki oraz z rozpoznaniem zakażenia SARS-CoV-2. http://www. neonatologia.edu.pl/index.php?option=com_content\&view=articl e\&id=215: postepowanie-z-noworodkiem-przy-podejrzeniu-potwierdzeniu-zakazenia-sars-cov-2-u-matki-oraz-z-rozpoznaniem-zakazenia-sars-cov-2\&catid=8\&ltemid $=103$.

10. Reale SC, Lumbreras-Marquez $\mathrm{Ml}$, King $\mathrm{CH}$, et al. Patient characteristics associated with SARS-CoV-2 infection in parturients admitted for labour and delivery in Massachusetts during the spring 2020 surge: A prospective cohort study. Paediatr Perinat Epidemiol. 2021; 35(1): 24-33, doi: 10.1111/ppe.12743, indexed in Pubmed: 33496995.

11. Allotey J, Stallings $E$, Bonet $M$, et al. for PregCOV-19 Living Systematic Review Consortium. Clinical manifestations, risk factors, and maternal and perinatal outcomes of coronavirus disease 2019 in pregnancy: living systematic review and meta-analysis. BMJ. 2020; 370: m3320, doi: 10.1136/bmj.m3320, indexed in Pubmed: 32873575.

12. Public Health England. COVID-19: investigation and initial clinical management of possible cases 2020. https://www.gov. uk/government/publications/wuhan-novel-coronavirus-initialinvestigation-of-possible-cases/investigation-and-initial-clinical-management-of-possible-casesof-wuhan-novel-coronavirus-wn-cov-infection.

13. Vouga M, Favre G, Perez OM, et al. Maternal and Obstetrical Outcomes in a Cohort of Pregnant Women Tested for SARS-CoV-2: Interim Results of the COVI-Preg International Registry. SSRN Electronic Journal. , doi: $10.2139 /$ ssrn.3684424.

14. Zimmermann $\mathrm{P}$, Curtis $\mathrm{N}$, Zimmermann $\mathrm{P}$, et al. Coronavirus Infections in Children Including COVID-19: An Overview of the Epidemiology, Clinical Features, Diagnosis, Treatment and Prevention Options in Children. Pediatr Infect Dis J. 2020; 39(5): 355-368, doi: 10.1097/INF.0000000000002660, indexed in Pubmed: 32310621.

15. Donati S, Corsi E, Salvatore MA, et al. Childbirth Care among SARS-CoV-2 Positive Women in Italy. Int J Environ Res Public Health. 2021; 18(8), doi: 10.3390/ijerph18084244, indexed in Pubmed: 33923642.

16. Cardona-Pérez J, Villegas-Mota I, Helguera-Repetto A, et al. Prevalence, clinical features, and outcomes of SARS-CoV-2 infection in pregnant women with or without mild/moderate symptoms: Results from universal screening in a tertiary care center in Mexico City, Mexico. PLOS ONE. 2021; 16(4): e0249584, doi: 10.1371/journal.pone.0249584.

17. Ciapponi A, Bardach A, Comandé D, et al. COVID-19 and pregnancy: An umbrella review of clinical presentation, vertical transmission, and maternal and perinatal outcomes. PLoS One. 2021; 16(6): e0253974, doi: 10.1371/journal.pone.0253974, indexed in Pubmed: 34185807.

18. Jering KS, Claggett BL, Cunningham JW, et al. Clinical Characteristics and Outcomes of Hospitalized Women Giving Birth With and Without COVID-19. JAMA Intern Med. 2021; 181(5): 714-717, doi: 10.1001/jamainternmed.2020.9241, indexed in Pubmed: 33449067.

19. Lokken E, Huebner E, Taylor G, et al. Disease severity, pregnancy outcomes, and maternal deaths among pregnant patients with severe acute respiratory syndrome coronavirus 2 infection in Washington State. American Journal of Obstetrics and Gynecology. 2021; 225(1): 77.e1-77. e14, doi: 10.1016/j.ajog.2020.12.1221.

20. Nayak M, Panda S, Panda S, et al. Neonatal outcomes of pregnant women with COVID-19 in a developing country setup. Pediatrics \& Neonatology. 2021; 62(5): 499-505, doi: 10.1016/j.pedneo.2021.05.004.

21. Chen $Y$, Peng $H$, Wang $L$, et al. Infants Born to Mothers With a New Coronavirus (COVID-19). Front Pediatr. 2020; 8: 104, doi 10.3389/fped.2020.00104, indexed in Pubmed: 32266184.

22. Angelidou A, Sullivan K, Melvin P, et al. Association of Maternal Perinatal SARS-CoV-2 Infection With Neonatal Outcomes During the COVID-19 Pandemic in Massachusetts. JAMA Network Open. 2021; 4(4): e217523, doi: 10.1001/jamanetworkopen.2021.7523.

23. Zhu H, Wang L, Fang $C$, et al. Clinical analysis of 10 neonates born to mothers with 2019-nCoV pneumonia. Translational Pediatrics. 2020; 9(1): 51-60, doi: 10.21037/tp.2020.02.06. 